6. HisTORIA DE LOS DOGMAS 

Revista de Estudios Histórico-Jurídicos

[Sección Historia de los Dogmas]

XXXVI (Valparaíso, Chile, 2014)

[pp. 345 - 364]

\title{
LA BUENA FE MERCANTIL EN LA TRADICIÓN JURÍDICA OCCIDENTAL
}

[Good Faith in Commercial Matters in the Western Legal Tradition]

\author{
Lorena Carvajal Arenas*
}

Pontificia Universidad Católica de Valparaíso, Chile

\section{RESUMEN}

Este artículo muestra cómo la buena fe ha adquirido un significado preciso en diferentes épocas del derecho occidental y se muestran los factores históricos que han incidido en el significado de este principio en diferentes etapas. Se concluye que la buena fe es un concepto moldeable. Sus atributos permiten prever su evolución en las culturas jurídicas más importantes del derecho occidental.

Palabras clave

Buena fe-Bona fides-Aequitas-Dolo.
Abstract

This article shows the accurate meanings good faith has been given to over the different periods in Western law and shows the historical factors that, at different stages, have had an influence on the meaning of this principle. We conclude that good faith is a shapeable concept, attributes of which allow forecasting its evolution in the most important legal cultures of the Western law.

KeYwords

Good faith - Bona fides - Aequitas Fraud.

RECIBIDO el 24 de abril y ACEPTADO el 26 de julio de 2014

* Profesora de derecho comercial en la Facultad de Derecho de la Pontificia Universidad Católica de Valparaíso, Chile. Dirección postal: Avenida Brasil 2950, Valparaíso, Chile. Dirección electrónica: lorena.carvajal@ucv.cl 


\section{INTRODUCCIÓN. \\ EL PROBLEMA DEL SIGNIFICADO ${ }^{1}$}

El rol preponderante de la buena fe en los intercambios comerciales, tanto en contextos universales como locales, ha sido una constante a través de los tiempos ${ }^{2}$. Por lo tanto, se ha considerado procedente investigar la razón que subyace a la perdurable presencia del principio.

Una primera explicación es la conexión de la buena fe con uno de los temas cardinales de toda la tradición filosófica europea, tanto jurídica como política: el diálogo entre las teorías de la libertad y de la responsabilidad ${ }^{3}$. A la base de la teoría contractual se encuentra el individuo y su libertad; su responsabilidad hacia la contraparte es integral a esta premisa. La buena fe surge a partir de esta tensión. La siguiente idea de Rodotà contribuye a la mejor comprensión acerca de la forma cómo la buena fe concreta la responsabilidad hacia el otro: "Si nos detenemos en la antigua definición de contrato de Durkheim como 'una tregua provisional entre las partes' podemos decir que la buena fe es la regla de las reglas de esa tregua. Es aquélla que define cómo esa tregua ha de ser gobernada" ${ }^{4}$. Tal juicio revela la importancia y la actualidad de la buena fe, puesto que tanto la libertad contractual como la responsabilidad son prominentes en los contratos.

Sin embargo, la buena fe ha generado preocupación por el paternalismo que podría implicar la imposición de criterios con rasgos morales en áreas comerciales donde la libre determinación debería prevalecer. En Inglaterra, por ejemplo, a fines del siglo XVIII el liberalismo económico reinante impidió a Lord Mansfield aplicar la buena fe como una regla general de los contratos ${ }^{5}$. Paradójicamente,

${ }^{1}$ Este artículo acepta como premisa que el principio de la buena fe tiene un significado propio. El argumento no es baladí si se considera que el autor norteamericano Summers es ampliamente conocido por su noción excluyente de la buena fe, quien, en breve, sostiene que este principio carece de contenido propio y sólo sirve para identificar situaciones de mala fe. El autor dice que: "Una vez que la forma relevante de mala fe se identifica, el jurista puede, si lo desea, asignar un significado específico a la buena fe a través de la formulación de un 'opuesto' para las especies de mala fe que son descartadas”. Summers, R., The Conceptualisation of Good Faith in American Contract Law: A General Account, en Zimmermann, Reinhard - WhitTaKer, Simon (editores), Good faith in European Contract Law (Cambridge, Cambridge University Press, 2000), pp. 119-20.

${ }^{2}$ En civil law la buena fe no sólo es un tema clásico - es el fulcro del derecho de las obligaciones-, sino que, además, su importancia se está incrementando. Por ejemplo, recientemente un número de parágrafos inspirados en la buena fe fueron incorporados al BGB. En el common law la buena fe está ganando terreno. En el derecho transnacional, tanto en convenciones internacionales como en "soft law", la buena fe también tiene un rol preponderante. Véase: MEYER, Rudolf, Bona fides und lex mercatoria in der europäischen Rechtstradition (Göttingen, Wallstein, 1995); y Zimmermann, Reinhard, The New German Law of Obligations. Historical and Comparative Perspective (Oxford, Oxford University Press, 2005).

${ }^{3}$ WiEACKer, Franz, Foundations of European Legal Culture, en American Journal of Comparative Law, 38 (1990), p. 1.

${ }^{4}$ RoDOTÀ, Stefano, Il tempo delle clausule generali, en VV. AA., Il principio della buona fede (Milano, Giuffrè, 1987), pp. 247 ss.

${ }^{5}$ AтіYAн, Patrick, The Rise and Fall of Freedom of Contract (Oxford, Oxford University Press, 1979), p. 168. 
hoy el "common law" de los Estados Unidos, cuya economía está basada en el liberalismo, ha consagrado el principio de la buena fe en el Uniform Commercial Code, por ejemplo. Este principio también es cardinal en la nueva lex mercatoria ${ }^{6}$, en un mundo de transacciones internacionales marcado por el liberalismo. A partir de esta constatación surgen algunas interrogantes: ¿La cláusula general de la buena fe contribuye a la eficiencia del derecho de los contratos comerciales o representa un elemento disuasivo para los comerciantes? ¿Los comerciantes necesitan la buena fe en sus relaciones contractuales? Desde el punto de vista de la práctica mercantil, es necesario clarificar estas dudas antes de incorporar la buena fe en los contratos a través de referencias a sistemas jurídicos nacionales o transnacionales que la consagran. Por lo tanto, al objetivo teórico de esta investigación -esto es, la determinación de la razón que subyace al rol preponderante de la buena fe mercantil- se une este objetivo práctico.

Aquí se postula la eficacia de la buena fe en contratos comerciales regidos por derechos universales ${ }^{7}$ y nacionales. Además, se considera que la presencia del principio y su importancia a través de los siglos se deben a la mutación que los conceptos de fides y bona fides han experimentado y a la consecuente flexibilidad de interpretación de los mismos.

Para verificar este postulado se analiza la evolución de la buena fe en derecho romano, en derecho medieval y en los derechos nacionales a inicios de la edad contemporánea. En este último período, se examina el derecho civil y el derecho anglosajón. Respecto al common law, la presente investigación postula dos teorías para explicar la razón de la inexistencia de la buena fe como criterio rector en este sistema.

El artículo se estructura fundamentalmente en tres párrafos: buena fe en derecho romano; bona fides en el derecho romano post clásico, en la Alta Edad Media y en la primera parte de los Tiempos Modernos; y buena fe en los códigos. Esta última sección contiene un párrafo dedicado a Inglaterra.

${ }^{6}$ 'La lex mercatoria requiere que los contratos sean ejecutados de buena fe". Laudo de la Cámara de Comercio Internacional de París $N^{\circ}$ 5904, en Journal du Droit International; Law \& Just., 115 (1989), p. 1107. Original en francés. Para conocer la relación entre la lex mercatoria actual y la lex mercatoria medieval, puede consultarse: VOLCKART, O. - MANGELS, A, Are the Roots of the Modern "lex mercatoria" Really Medieval? en Southern Economic Journal, 65 (1999), pp. 427 ss.

${ }^{7}$ La noción de universalidad se considera desde un punto de vista geográfico. En este sentido, el concepto difiere de acuerdo a la época. Por ejemplo, en la segunda parte de este artículo "universal" equivale a "perteneciente al mundo romano". Cfr. Cic., De off. 3,17,69; Gai. 1,1. En cambio, en época contemporánea "universal” debe entenderse en su real sentido, es decir, que pertenece o se extiende a todo el mundo. Un ejemplo son los Principios de UNIDROIT sobre Contratos Comerciales Internacionales, los cuales -en su calidad de "soft law"- son aplicables universalmente. Véase: BONELl, Michael Joachim, Un "codice" internazionale del diritto dei contratti. I Principi UNIDROIT dei Contratti Commerciali Internazionali (Milano,Giuffrè, 2006). 


\section{LA BUENA FE EN DERECHO ROMANO ${ }^{8}$}

La administración de justicia entre ciudadanos durante el período clásico del derecho romano se llevó a cabo bajo la supervisión de una magistratura única: el praetor. Este magistrado preparaba las decisiones de los jueces privados (iudices privati), les otorgaba autoridad para recoger las pruebas y para decidir los casos conforme a unas instrucciones escxritas (formulae). Al inicio de su período anual, el pretor informaba al público -a través del Edicto- esquemas abstractos de acciones, cuyos términos se resumían en fórmulas (tantas cuantas fueren las situaciones subjetivas típicas consideradas dignas de tutela) ${ }^{9}$.

En los albores del proceso formulario (siglo III-II a. C.) la fórmula se basaba en el ius civile. El concepto de buena fe devino parcialmente importante en aquellos casos que debían decidirse conforme al ius civile, a consecuencia de una cláusula que se insertaba en la fórmula a requerimiento del demandado: la exceptio doli ${ }^{10}$, con la cual se podía absolver al demandado que había sido víctima de argucias de parte de su cocontratante que lo estaba demandando ${ }^{11}$. Esto significó una evolución respecto de la situación anterior donde, si la situación no estaba contemplada en el ius civile, entonces no podía ser exigida. En un momento posterior, no se sabe en cuál, el edicto comenzó a contener acciones basadas, no en el viejo civil oportere, sino en un oportere ex fide bona, en la cual no solo se tomaba en cuenta el eventual dolo sino incluso la culpa.

El ius civile en la antigua Roma era el derecho de los ciudadanos romanos. Cuando los cives Romani comenzaron a incrementar sus relaciones con otras comunidades - comunidades latinas, en un comienzo, y mediterráneas, posteriormente- se hizo necesario reconocer acuerdos comerciales entre los ciudadanos romanos y los miembros de estas comunidades. Este fenómeno se considera el

${ }^{8}$ No obstante la minuciosidad del análisis, éste no es un estudio exclusivamente dedicado a la buena fe en derecho romano. Estudios previos sobre la materia y el objetivo de esta investigación relevan al presente artículo de emprender dicha tarea. Véase una excelente revisión de la literatura sobre buena fe en derecho romano en: FASCIONE, L., Cenni bibliografici sulla bona fides, en Studi sulla buona fede (Milano, Giuffrè, 1975), pp. 51 ss.

${ }^{9}$ Véase un breve resumen y, al mismo tiempo, una valiosa descripción del officium del praetor y de la importancia de los juristas en torno a él, los iurisconsulti, en: WIEACKER, Franz, The Importance of Roman Law for Western Civilization and Western Legal Thought, en Boston College International and Comparative Law Review, 4 (1981), pp. 257 ss.

${ }^{10}$ Whittaker, Simon - Zimmermann, Reinhard, Good faith in European Contract Law: Surveying The Legal Landscape, en ZimMERMANn y WhitTAKER (editores), cit. (n. 1), p. 16, manifiestan: "La exceptio doli se expresa a través de la siguiente alternativa: 'si in ea re nihil dolo malo AA factum sit neque fiat ' ('si en esta materia nada se haya hecho ni se haga con dolo por el demandante Aulo Agerio’). Específicamente, la segunda alternativa (neque fiat-ni se haga-) determina que la exceptio doli sea un instrumento poderoso para alcanzar una solución justa, en cuanto invita a una respuesta que identifica el dolus no tanto con una conducta personal reprochable, sino más bien en la falta de equidad o injusticia que derivaría si triunfa la acción del demandante".

${ }^{11}$ El desarrollo de la exceptio doli generalis en derecho alemán puede verse en: ZIMMERMANN, Reinhard, Roman Law, Contemporary Law, European Law. The civilian Tradition Today (Oxford, Oxford University Press, 2001), pp. 83 ss. 
factor decisivo del origen y desarrollo de la iurisdictio del pretor peregrino ${ }^{12}$ y de la configuración del ius gentium. Las convenciones en el contexto del ius gentium obligaban a las partes basadas en la fides, en la ética comercial y en las costumbres mercantiles ${ }^{13}$. Por lo tanto, fides en el ius gentium presuponía, no simplemente una conducta justa sino también, respeto a las costumbres mercantiles, conforme a los estándares de esa época ${ }^{14}$.

El rol de la fides en derecho romano fue muy importante, puesto que suprimió la tensión permanente entre ius strictum y ius aequum ${ }^{15}$. Wieacker señala que el pretor "estableció nuevos estándares éticos en los bonae fidei iudicia. Igualmente, el pretor adaptó el decaído derecho de una sociedad tribal y agraria a las nuevas necesidades del comercio" 16 .

En la fórmula del pretor el juez recibía la instrucción de requerir al demandado, en aquellos casos que el demandante probara el incumplimiento de la obligación contractual de cumplir todo lo que el primero tenía que dar o hacer conforme con la buena fe. No existían indicaciones generales, sino soluciones particulares y, debido a que el principio no tenía un contenido a priori, la vía judicial fue esencial para concretar el concepto como derecho aplicable. Esto significa que los jueces concretizaban el concepto de la buena fe de acuerdo a las situaciones específicas que conocían ${ }^{17}$.

A pesar de la estrecha relación entre buena fe y procedimiento formulario, la fides no puede reducirse a un ámbito procedimental. La fides fue una idea central del pensamiento legal y político de Roma ${ }^{18}$. La fides precedió a la bona fides. Existía, sin embargo, un vínculo entre estos dos conceptos ${ }^{19}$. La fides se entendía como mantenerse fiel a su propia palabra; e implicaba vínculos de sujeción por el abandono de una persona o una ciudad a otra. En tanto, la bona fides se aplicaba para verificar el contenido implícito de los contratos celebrados, pues se aludía a un vínculo que había superado al abandono unilateral (por ejemplo, las relaciones entre patrono y cliente) y se refería a un vínculo recíproco de fides: "Dos personas quedan entregadas, la una a la otra, a la lealtad de la palabra empeñada en un acto no formal"20.

${ }^{12}$ Véase: Serrao, Feliciano, La "iurisdictio" del pretore peregrino (Milano, Giuffrè, 1954).

${ }^{13}$ Cfr. Lombard, G, Ricerche in tema di "ius gentium" (Milano, Giuffrè, 1946).

${ }^{14}$ Véase: WIEACKER, Franz, El principio de la buena fe (traducción castellana de José Luis Carro, Madrid, Civitas, 1982).

${ }^{15}$ D. 1,1,7,1: "Ius praetorium est, quod praetores introduxerunt adiuvandi vel supplendi vel corrrigendi iuris civilis gratia propter utilitatem publica"; buena parte de esta afirmación se aplica a la superación del ius civile por el edicto.

${ }^{16}$ WIEACKER, Franz, The Importance, cit. (n. 9), p. 266.

${ }^{17}$ Cfr. Cardilli, Riccardo, La "buona fede" come principio di diritto dei contratti. Diritto Romano e America Latina, en Garofalo, Luigi (editor), Il ruolo della buona fede oggettiva nell esperienza giuridica storica e contemporanea: atti del convegno internazionale di studi in onore di Alberto Burdese (Padova, Cedam, 2003), pp. 342 ss.

${ }^{18}$ Cfr. D'Ors, Álvaro, Derecho privado romano (Pamplona, Ediciones Universidad de Navarra, 1968), p. 30.

${ }^{19}$ Respecto al vínculo histórico y conceptual entre la noción arcaica de fides y la cláusula $e x$ fide bona, véase: LOMBARDI, L, Dalla "fides" alla "bona fides" (Milano, Giuffrè, 1961).

${ }^{20}$ SAMPER, Francisco, Derecho romano (Santiago, Ediciones Universidad Internacional SEK, 1991), p. 20. 
Sin embargo, fides (como fuente remota de obligaciones) también presentaba un carácter práctico digno de destacar, pues fue adoptada en el ius gentium como base de las relaciones contractuales entre los comerciantes. Por último, en este período, el carácter ético de la buena fe también era importante, desde que los bonae fidei iudicia se usaban preferentemente para imponer sanciones en casos de comportamientos fraudulentos ${ }^{21}$.

En resumen, en derecho romano sobresale el carácter utilitario de la buena fe, puesto que se invocaba en la fórmula -no como fuente de obligaciones- sino que para extender la discreción del juez en relación a su sentencia.

El concepto de la buena fe en el procedimiento romano se concretaba a través de la actividad de los iurisconsulti, los juristas que asistían al pretor en la creación de la fórmula. Estos expertos eran capaces de extraer la esencia de cada caso y especificar el problema legal como una questio iuris. De esta forma, la bona fides fue uno de los agentes más fructíferos en el desarrollo del derecho contractual.

\section{LA “BONA FIDES” EN EL DERECHO ROMANO POST CLÁSICO, en la Alta Edad Media y en la primera parte de la Época Moderna}

Como es sabido, el Corpus iuris civilis es una compilación que fue compuesta a principios del siglo VI en el Imperio Romano de Oriente, a instancia política del emperador Justiniano. En ese período el procedimiento privado hacía muchos siglos que había evolucionado desde la antigua fórmula del pretor hacia un sistema burocrático: la cognitio extra ordinem. En este sistema la decisión de los casos provenía de un dependiente del emperador; la guía de los jurisconsultos desapareció. Por lo tanto, instituciones sustanciales del derecho declinaron en su nivel de elaboración. Esto se había con solidado con la instauración definitiva del absolutismo por parte del emperador Diocleciano (284 d.C.) y a la decadencia radical de la cultura clásica. Los textos de la jurisprudencia precedente (proveniente de los iurisconsulti) fueron llamados iura en contraposición a las prescripciones del emperador, llamadas leges. Sin embargo, el Corpus iuris Justinianeo tuvo lugar en un ambiente de revalorización de la jurisprudencia clásica por parte de las escuelas de derecho bizantinas de los siglos V y VI.

Durante la época post clásica, a partir del principio de la buena fe fue posible derivar reglas de conducta para las partes. De esta forma, la buena fe dejó de ser una característica de algunos tipos de procesos, aquellos llamados bonae fidei iudicia en el antiguo sistema -como se ha mencionado precedentemente-, para asumir un significado sustancial.

En los reinos de Europa continental la ley de Justiniano era ius commune, aplicable en todo caso de ausencia de fuentes de derecho especial regional ${ }^{22}$. El

${ }^{21}$ Cfr. Schermaier, M. J., Bona fides in Roman Contract Law, en Zimmermann - Whittaker, cit. (n. 1), pp. 63 ss.

${ }^{22} \mathrm{El}$ ius commune se aplicó en Europa continental desde el s. X hasta el procedimiento de codificación en el s. XVIII. En principio, Inglaterra estuvo excluida, puesto que al momento de la invasión normanda (s. XI) existía un derecho desprovisto de influencia romana. Sin embargo, esta situación evolucionó: ver n. 31 y el texto referido en este artículo. 
renacimiento del derecho romano clásico tuvo lugar en Italia a inicios del siglo $\mathrm{XI}$ con el trabajo de los glosadores de Bolonia ${ }^{23}$.

La escuela de Bolonia consideraba el derecho romano como derecho aplicable. El método adoptado por ésta devendría aquél aplicado por los sistemas continentales hasta el día de hoy: la decisión se construye por la vía de la subsunción de un caso a un texto o estatuto de carácter abstracto.

Por otra parte, el derecho comercial italiano permeó completamente Europa occidental ${ }^{24}$. En este proceso la influencia del derecho romano fue enorme. En algunas ciudades italianas (Como, Plasencia, Cremona, Bolonia, Florencia y Génova) los estatutos mercantiles expresamente declaraban que el derecho romano debía ser aplicado en caso que los mismos estatutos no previeran la solución ${ }^{25}$. Las razones que explican tal reenvío eran la auctoritas del derecho romano y la necesidad de contar con un derecho común. El derecho canónico también fue influyente. Aquí el elemento de la buena fe era muy fuerte. Conforme a ella, la sola palabra de un hombre honesto debía ser suficiente causa para un contrato ${ }^{26}$. La buena fe proveniente de la Iglesia se asociaba con los principios de la aequitas mercatoria tendente a proveer a los comerciantes de un derecho flexible y, al mismo tiempo, respetable para gobernar sus contratos - principalmente basados en el crédito en esos tiempos-. La buena fe fue tempranamente aceptada por la lex mercatoria para proteger contra las ventajas indebidas provenientes de resquicios legales. Sobre la base de este principio el mero consenso entre las partes del contrato era suficiente para obligar al contratante. Por lo tanto, en la evolución del derecho la buena fe facilitó el intercambio comercial e introdujo valores sociales en las transacciones.

${ }^{23}$ Los estudiosos de las escuelas de derecho de Italia, Francia y Alemania de los siglos XI y XII son identificados como glosadores. Ellos estudiaron el derecho romano basados en los Digestae, el Codex de Justiniano, las Authenticae (un compendio traducido al latín de selectas constituciones de Justiniano, promulgadas en griego después de la vigencia del Codex y, por lo tanto, llamadas Novellae) y el manual de derecho llamado Institutiones Iustiniani. Todo esto compilado formaba el Corpus iuris civilis. Este título es sólo una invención de los impresores del siglo XVI. Véase en lo relativo al nombre atribuido a esta compilación: THORnE, S. E., Statuti in the Post-Glossators, en Speculum, 11 (Cambridge Ma., 1936), pp. 452 ss. Los glosadores llevaron a cabo detallados estudios de los textos, los cuales resultaron en colecciones de explicaciones. Para su elaboración usaron un método desconocido por los propios romanos; ellos insistían en que las contradicciones en los textos eran sólo aparentes y, por lo tanto, trataron de armonizar las fuentes en la convicción que para cada questio iuris existía sólo una regla. Los glosadores trataron cada cuestión de modo dialéctico, el cual caracteriza el escolasticismo medieval.

${ }^{24}$ Las ciudades italianas forjaron los fundamentos del derecho comercial y marítimo moderno de Europa occidental. La influencia de las instituciones y de los modelos de tribunales comerciales y marítimos italianos fue notable sobre: las ciudades-puerto españolas (Barcelona es un caso importante, pues produjo el conocido cuerpo normativo Consolat de Mar); ciudades del Sur de Francia, tales como Marseilles, Montpellier, Nimes y Narbonne; como también ciudades y estados del Norte Europeo como Champagne, Flandes, Geneva, Besancon, Frankfort on the Main, Leipzig y Colonia. Cfr. Holdsworth, William, A History of English Law (3a edición, London, Sweet \& Maxwell, 1945), V, pp. 60-154.

${ }^{25}$ SAnBorn, Frederic Rockwell, Origins of the Early English Maritime and Commercial Law (Buffalo, Hein \& Co., 2002), pp. 199-200.

${ }^{26}$ Véase: LATTES, Alessandro, Il diritto commerciale nella legislazione statutaria delle città italiane (Milano, Hoepli, 1884), p. 123. 
En Inglaterra el derecho romano comenzó a ejercer su influencia desde el siglo XII a través de las siguientes vías:

i) La enseñanza de la literatura legal de los glosadores boloñeses. Las doctrinas de los glosadores e incluso el derecho romano medieval pre-boloñés influyeron la organización intelectual del common law inglés, y especialmente la equidad ${ }^{27}$. Durante el período medieval hubo un acercamiento entre la buena fe (bona fides) y la equidad (aequitas) ${ }^{28}$;

ii) El derecho canónico, el cual era una síntesis de fuentes eclesiásticas y de interpretación medieval del derecho romano, era aplicado en las cortes de la Iglesia inglesa, cuya jurisdicción incluía casos relacionados con contratos;

iii) La aplicación de los principios del derecho civil (es decir, una versión del ius commune) por la Corte de Almirantazgo ${ }^{29}$, la Cámara Estrellada (Star Chamber) y las cortes eclesiásticas ${ }^{30}$.

A propósito de la influencia del derecho romano en Inglaterra, es oportuno citar a Wieacker: "El common law y la equidad de la órbita anglosajona han compartido, desde la primera parte del Alto Medioevo, la tradición Europea del ius commune y el ius utrumque" 31 .

En términos generales, es posible identificar tres períodos de contacto entre el sistema legal inglés y el derecho civil:

i) Durante la primera etapa de desarrollo de la justicia real del siglo XII;

ii) En el siglo XVI cuando el proceso es conducido y la justicia administrada en la Corte de Almirantazgo de acuerdo con el derecho civil ${ }^{32}$; y

iii) Un período final de influencia aparece a fines del siglo XVII e inicios del siglo XVIII bajo el liderazgo de Lord Mansfield ${ }^{33}$.

\footnotetext{
${ }^{27}$ Véase: Vinogradoff, Paul, Roman Law in Medieval Europe (2a edición, Oxford, Oxford Clarendon Press, 1929).

${ }^{28}$ Véase: Fauvarque-Cosson, Bénédicte - Mazeaud, Denis (editores), European Contract Law, Materials for a Common Frame of Reference: Terminology, Guiding Principles, Model Rules (Munich, Sellier, 2008), p. 154. En la actualidad, se ha sugerido que la equidad cumple la función de la buena fe en el derecho comercial inglés [TetLeY, William, Good Faith in Contract. Particularly in the Contracts of Arbitration and Chartering, en Journal of Maritime Law and Commerce, 35 (2004, p. 572]. Sin embargo, la equidad no es un concepto general que permite la entrada de nociones generales de corrección (fairness). La equidad es usada por los jueces como último resorte, excepto en áreas enteramente cubiertas por ella, tales como trust, agencia, sociedades y derecho de quiebras.

${ }^{29}$ Senior, William, Doctor's Commons and the Old Court of Admiralty; a Short History of the Civilians in England (London, Longmans, 1922), declara: "La historia temprana de la Corte de Almirantazgo es reconocidamente oscura. No se conoce el año de su comienzo. La mayor autoridad solamente nos dice que su origen puede encontrarse 'con tolerable certeza' entre 1340 y 1357 , y que fue instituida para casos de piratería y causas relativas a 'robos violentos' hechos por o contra soberanos extranjeros".

${ }^{30}$ Cfr. WIEACKer, Franz, The Importance, cit. (n. 9), pp. 259 s.

${ }^{31}$ WIEACKER, Franz, Foundations, cit. (n. 3), p. 6. El mismo autor explica: "El término ius utrumque se refiere a la combinación del secular neo-derecho romano (acondicionado por los glosadores y comentadores de la Universidad de Bolonia) y el derecho canónico de la Iglesia Católico-Romana aplicada por las cortes eclesiásticas de Europa".

${ }^{32}$ Ibid., p. 15

${ }^{33}$ Véase Donahue, Charles, The Civil Law in England, en Yale Low Journal, 84 (1974), p.
} 
Además, en Inglaterra en el siglo XIV la ley aplicable en las cortes mercantiles era la costumbre mercantil, un cuerpo normativo cuya base sustancial era derecho civil. La lex mercatoria y la lex maritima eran diferentes al common law ${ }^{34}$. Senior se pronuncia sobre este punto: "Podemos estar seguros de que los hombres buenos del pueblo, quienes administraban justicia en los muelles de Ipswich y Bristol en el siglo XIV no estaban concientes de conexión alguna con el Digesto. Ellos sabían que la ley que administraban no era el common law de Inglaterra, reconocido y admitido; ellos eran cercanos a las "piepowder courts" de las ferias que administraban la lex mercatoria, la cual tampoco era common law"35.

En la Edad Moderna, a partir del siglo XVI, como resultado de los descubrimientos en el Nuevo Mundo, el comercio aumentó. Por primera vez el comercio marítimo se llevó a cabo a través de nuevas rutas, y de esa forma alcanzó los lugares más distantes del planeta. La antigua sociedad mercantil sintió los efectos de estos eventos y experimentó una metamorfosis; esto marcó el comienzo de una nueva era. En esta época Europa experimentó un desarrollo cultural conocido como Humanismo ${ }^{36}$. Este fenómeno complejo significó en derecho el redescubrimiento del derecho romano clásico ${ }^{37} \sin$ interpolaciones y glosa; también implicó que los humanistas despreciaban a Justiniano por su obra -el Corpus iuris civilis- (éstos eran los llamados los anti-Triboniano) ${ }^{38}$. Lo que este grupo de personas no podía perdonar a Justiniano era que hubiese recogido solo parte del antiguo saber romano. Ellos también criticaban a los juristas de la Edad Media, porque odiaban la discontinuidad en relación con las líneas de la jurisprudencia clásica ${ }^{39}$. Por lo

167.Véase también: Thorne, S. E, Henry de Bracton 1268-1968: a Lecture Delivered in Exeter on 27th September 1968 on the occasion of the 700th anniversary of the death of Henry de Bracton (Exeter, University of Exeter 1970); y MaItLand, Frederick William, English Law and the Renaissance (Cambridge, Cambridge University Press, 1901).

34 "Así como el globo terráqueo se compone de tierra y aguas, de la misma forma el cuerpo de la lex mercatoria está conformado por las costumbres mercantiles y las leyes marítimas, las cuales están unidas como los mares y la tierra": MALYNES, Gerard, "Consuetudo vel lex mercatoria" (1622, reimpresión Oxford, Professional Books, 1981).

${ }^{35}$ Senior, William, cit. (n. 29), p. 20 s. Véase también: Gross, Charles, The Court of Piepowder, en The Quarterly Journal of Economics, 20 (Oxford, 1906) 2, pp. 231-249.

${ }^{36}$ El Humanismo fue un movimiento intelectual en Europa, el cual comenzó en el siglo XIV al tiempo de la Reforma y el Renacimiento. Los Humanistas reaccionaron contra el escolasticismo medieval, a través del énfasis en el intelecto humano y los logros culturales, en vez de aspectos tales como: la intervención divina; la brevedad y la miseria de la vida; y la necesidad de escape. El movimiento comenzó en Italia con un gran acento en los estudios de los clásicos de las antiguas civilizaciones romana y griega. El redescubrimiento de los escritos clásicos y la relajación de la censura intelectual, la cual había caracterizado a la Iglesia medieval, condujo a un incremento de los estudios filosóficos, científicos y sociales. No es un accidente que la cúspide de la actividad humanista coincida con el primer gran período de la investigación científica en Europa, con el trabajo de los observadores y pensadores tales como Bacon, Copérnico, Galileo, Harvey y Paracelso.

${ }^{37}$ El período clásico se extendió desde el año 27 a.C., aproximadamente, hasta mediados del siglo III d.C.

${ }^{38}$ El jurista bizantino Triboniano (m. 545) presidió la comisión compiladora del Corpus iuris civilis.

${ }^{39}$ Véase: MaffeI, Domenico, Gli inizi dell Umanesimo giuridico (Milano, Giuffrè, 1956), 
tanto, tal como ocurrió en la época clásica del derecho romano, la Edad Moderna también fue testimonio de la buena fe como principio rector de la escena mercantil ${ }^{40}$. Así, se dijo: "bona fides est primum mobile ac spiritus vivificans commercii" ${ }^{41}$.

En el siglo XVIII lord Mansfield absorbió gran parte de la lex mercatoria -y con ésta algunas ideas de la tradición del derecho civil continental- en el derecho inglés ${ }^{42}$. A pesar de que el contacto entre el derecho civil y el derecho inglés tuvo lugar durante este período a través de la lex mercatoria, cada sistema continuó su propio sendero: el derecho continental consagró la buena fe como un principio general, mientras el derecho de Inglaterra reconoció la buena fe sólo en casos particulares, por ejemplo en el contrato de seguros ${ }^{43}$.

A partir de lo expuesto en esta sección, es posible observar las siguientes características de la buena fe:

i) Durante el período post-clásico la buena fe asumió un significado sustantivo, esto es, se convirtió en un principio a partir del cual derivar reglas de conducta;

ii) El carácter universal de la buena fe fue preponderante durante el período medieval, porque era un elemento esencial de muchas áreas del derecho -derecho civil, derecho canónico y la lex mercatoria-, las cuales compartían el carácter cosmopolita. De esta forma, la "buena fe universal" llegó hasta Inglaterra, como parte del ius commune, de la lex mercatoria y del derecho canónico;

iii) La visión canónica de la buena fe asistió a los mercaderes y a sus tribunales para regular adecuadamente las nuevas formas de fraude y las prácticas abusivas. Por lo tanto, contribuyó a exigir altos estándares de corrección y lealtad -la esencia del comercio-.

passim. Este autor considera (ver p. 19) que el Humanismo en el derecho comenzó con el trabajo de Irnerius (1050-1130), quien descubrió (esto es, entendió primero) que todo el derecho es "hominum causa", aunque en ello seguía textos romanos incluidos en los Digesta de Justiniano

${ }^{40}$ SANBORN, Frederic Rockwell, cit. (n. 25), p. 262.

${ }^{41}$ CASAREgIS, Giuseppe Lorenzo Maria, Discursus legales de commercio ed de avariis (Genova, 1707), p. 144.

${ }^{42}$ Un reporte sobre la influencia del derecho civil y canónico en el derecho inglés puede encontrarse en: WIEACKer, Franz, Foundations, cit. (n. 3), pp. 6 ss.

${ }^{43}$ En contratos de seguros el principio ha sido desarrollado especialmente durante el período precontractual. Sin embargo, últimamente la buena fe ha sido invocada en la relaciones entre las partes después de la formación del contrato. Más importante: la House of Lords parece haber aceptado que las reclamaciones derivadas de un contrato de seguros están sujetas al principio de la buena fe. Véanse los casos emblemáticos: "Manifest Shipping Co Ltd v. Uni Polaris Shipping Co Ltd (The StarSea)" [2001] United Kingdom House of Lords, 1 (2001), en Weekly Law Reports, 2 (2001), p. 170; y "Banque Financière de la Cité SA v. Westgate Insurance Co Ltd", en AC. 2 (1991), p. 249 . Véanse las razones de la falta de desarrollo de la buena fe como un principio general del derecho inglés en la sección IV, parágrafo 2 de este trabajo. 


\section{LA BUENA FE EN LA CODIFICACIÓN}

\section{Panorama general ${ }^{44}$.}

Desde el punto de vista teórico, los códigos tienen su fundamento en el iusnaturalismo o en el derecho de la razón ${ }^{45}$, el cual surgió durante la primera fase de la Edad Moderna. El derecho de la razón perseguía deducir reglas generales o principios de derecho a partir de la racionalidad del ser humano. Buscaba un derecho que pudiera ser válido en absoluto y pretendía que los códigos fueran un compendio de normas justas ${ }^{46}$. En esta filosofía la buena fe es vista como "derecho natural", por lo tanto algunas normas imponen el deber de cumplir los acuerdos en buena fe y otros se refieren a la equidad como fuente de obligaciones. Estas normas son consideradas por los iusnaturalistas como universales y necesarias ${ }^{47}$.

Con todo, algunas manifestaciones del "derecho de la razón” relativas a la buena fe no fueron consagradas en los códigos. Por ejemplo, el iusnaturalista Samuel Pufendorf ${ }^{48}$-quien escribió a fines del siglo XVII, durante el período que precedió a la codificación- indica que si una causa original o subsecuente produce un desequilibrio entre obligaciones recíprocas, el derecho natural ordena que deban ser modificadas ${ }^{49}$. Sin embargo, esta postura no fue consagrada en el Code Civily tampoco en el Bürgerliches Gesetzbuch-donde aparece como producto de un desarrollo posterior $-{ }^{50}$.

${ }^{44}$ Este artículo ofrece un panorama general sobre la recepción de la buena fe en los códigos modernos. Los detalles acerca de la consagración del principio en los códigos pertenecientes al derecho continental y su desarrollo en el derecho anglosajón pueden revisarse en el siguiente artículo: CARVAJAL, Lorena, La buena fe en derecho continental y en derecho anglosajón, en VV. AA, Cuartas Jornadas de Derecho Comercial (en prensa).

${ }^{45}$ La Escuela del Derecho Natural moderna refuta derivar sus principios a partir de sistemas externos, tales como el derecho divino o el Corpus Iuris. A través del estudio racional y de la crítica a la naturaleza humana, los autores de esta escuela buscan evidencia y principios axiomáticos a partir de los cuales podrían deducir otras reglas more geometrico. El título "derecho de la razón" es, por lo tanto, más precisa que "derecho natural", el cual tiene otras connotaciones.

${ }^{46}$ Véase: WIEACKer, Franz, Foundations, cit. (n. 3), pp. 15-18.

${ }^{47}$ Ser un iusnaturalista significa sostener la noción de derecho natural a la base y con categoría superior al derecho positivo. Para conocer un debate acerca de qué significa ser iusnaturalista hoy, véase: RentTo, Juha-Pekka, Between Clarence Thomas and Saint Thomas: Beginnings of a Moral Argument for Judicial Jusnaturalism, en University of California Davis Law Review, 26 (1992), p. 727.

${ }^{48}$ Pufendorf, Samuel, De jure naturae et gentium libri octo (1688, traducción inglesa de C. H. Oldfather y W. A. Oldfather, Oxford, Clarendon Press, 1934).

${ }^{49}$ Es importante resaltar que, no obstante lo indicado en el cuerpo del artículo, PUFENDORF, Samuel, cit. (n. 48), p. 388, mantiene como criterio rector la validez de la regla pacta sunt servanda. Este autor señala que la fe y la confianza requieren que en la sociedad humana se mantengan nuestras promesas 'Si quae autem inter homines ineuntur pacta, illa sancte observanda esse, sociabilis natura hominis requirit'.

${ }^{50}$ El párrafo en cuestión, ibíd., p. 697, es el siguiente: "Ipsa tamen naturalis ratio ostendit, contractus onerosos esse bonae fidei, seu laxiorem admittere interpretationem ex aequo et bono; ideo quod cum aequa in illis versetur obligatio, exinde neuter contrahentium gravetur. Contra autem benefici contractus stricti iuris videntur, nec laxam eiusmodi interpretationem admittunt, aut ut quis ad quid amplius, quam quod expresse significavit, adstringatur". 
El triunfo del iluminismo, el derecho natural o el derecho de la razón están representados en el mentado Code Civi $\bar{P}^{1}$. Al momento de su promulgación, la razón se había convertido en el principio rector y su universalidad logró que el cuerpo legal se impusiera sobre la auctoritas del aún prestigioso Corpus iuris. Por ello, Van Caenegem dice que: "El método moderno y más abstracto deliberadamente siguió a aquel de las ciencias abstractas, porque el objeto de los juristas era realizar ciencia universal basada en proposiciones demostrables" 52 .

En el Code Civil, así como en otros códigos de la esfera del civil law, la regla de la buena fe se ubica en una sección llamada "Efecto de las obligaciones" (effects des obligations). Como se indicó anteriormente, la regla se basa en la idea iusnaturalista de un código como un conjunto de prescripciones de carácter general con el objeto de ser aceptado por todos los ciudadanos. En este sentido, el artículo 2 del Código suizo contiene la norma sobre la buena fe más omnicomprensiva, pues declara que ésta es un presupuesto esencial para ejercer cualquier derecho: 'Chacun est tenu d'exercer ses droit et d'exécuter ses obligations selon les règles de la bonne foi" ("Todos están obligados a ejercer sus derechos y a ejecutar sus obligaciones según las reglas de la buena fe”)

En consecuencia, los códigos establecen la buena fe como un principio general. Incluso el Código Civil alemán está estructurado de esta forma (la buena fe se consagra como un principio general en el parágrafo 242 BGB.), aun cuando los autores querían separar el Código del iusnaturalismo para alinearlo con los Pandectistas $^{53}$. La excepción está constituida por el Código Civil austriaco (ABGB.), el cual no considera la buena fe como un principio general. La prescripción que se podría acercar a la buena fe es la del parágrafo 914: "La interpretación de los contratos no debe basarse en el tenor literal de las expresiones usadas, sino más bien en la real intención de las partes. El contrato se construirá de acuerdo a la costumbre y el trato honesto".

La actitud desconfiada de los académicos europeos en relación a la buena fe se hizo cada vez más fuerte, debido a la convicción que ésta requería un juicio de valor para concretizarla. A consecuencia de dicha actitud, y también debido al

${ }^{51}$ El derecho natural tuvo un papel preponderante en el trabajo de los redactores y los padres teóricos del Código. Durante la Revolución el derecho natural fue constantemente invocado para justificar reglas y sistemas nuevos. A pesar de ello, el Código, en los hechos, estableció la primacía del estatuto y rechazó toda referencia expresa al derecho natural.

${ }^{52}$ Van Caenegem, R. C., An Historical Introduction to Private Law (Cambridge, Cambridge University Press, 1992).

${ }^{53}$ Los pandectistas alemanes del siglo XIX estudiaban el derecho romano basados en el Digesto o Pandectas del Corpus Iuris Civilis (534 a.C.). Su logro fue ordenar sistemática y lógicamente el derecho romano conforme a las circunstancias modernas. El trabajo de los pandectistas fue muy influyente en la preparación del BGB desde 1874 en adelante, puesto que durante el siglo XIX el derecho romano aún era importante y era el único derecho común en muchos territorios independientes de la región. Los pandectistas desarrollaron un método específico de interpretación llamado Begriffsjurisprudenz (jurisprudencia de los términos), el cual deducía la solución de los problemas legales a partir de fórmulas y términos conformes a la estricta lógica. Véase: Magnus, U., Some Thoughts on Germany's Contribution to European and Comparative Law, en Bracton Law Journal, 38 (2006), pp. 87 ss. 
declive de la école de l'exégèse ${ }^{54}$, el método sistemático se desarrolló en el derecho civil de Europa. Los sostenedores, principalmente en Alemania, organizaron un cuadro armónico de los regulae iuris, donde no tenía cabida la buena fe. Sin embargo, aquí la influencia del iusnaturalismo aún estaba viva y por eso, aunque los intérpretes no creían en los postulados de la naturalis ratio, tomaron de esa teoría la esencia del fenómeno legal.

Esta visión desconfiada de la regla de la buena fe se debió en parte al fenómeno histórico de la Revolución Industrial, el cual mudó radicalmente Europa. Por lo tanto, para evitar los riesgos de los preceptos "elásticos", los juristas alemanes del siglo XIX prefirieron no comentar acerca de esta regla. La idea de desviar la atención respecto de la buena fe en el contrato se explica por: i) El temor a los juicios de valor (necesarios para materializar la norma); y ii) El individualismo dominante, el cual requería que se considerara la voluntad de las partes y el rechazo a la posibilidad que el juez pudiera enriquecerla o corregirla.

A pesar de las premisas iuspositivistas propagadas en Alemania durante el siglo XIX, la buena fe está presente en el BGB. No obstante la rígida posición contra los postulados de la naturalis ratio y el hecho que los Pandectistas rechazaban todo residuo proveniente de la memoria metafísica, los estudiosos fracasaron en la exclusión de la buena fe del lenguaje jurídico. Tal vez pensaron que devendría un aforismo sin mayores consecuencias. Más tarde la realidad demostraría que el resultado fue exactamente el opuesto ${ }^{55}$.

\section{Inglaterra.}

Es interesante analizar separadamente el caso de Inglaterra porque en este país no prosperó el concepto de la buena fe, como un principio válido para el derecho de las obligaciones y de los contratos.

Generalmente, esta situación se explica por la primacía de las doctrinas subjetivas clásicas de la libertad y santidad del contrato en el siglo XIX ${ }^{56}$ (sin embargo, esta investigación ofrece otras razones para explicar dicha situación). Se consideraba que todas las consecuencias de un contrato derivaban de la voluntad de aquellos que lo celebraban, quienes eran los mejores jueces de sus propias necesidades y circunstancias. De ello derivaba que la injusticia del acuerdo era irrelevante. Atiyah coloca la situación de la siguiente forma: "Esta ecuación de principios generales del derecho contractual con economía de libre mercado condujo a enfatizar el marco dentro del cual los individuos negocian y a un retroceso del interés en la justicia sustantiva y en la corrección. La teoría del contrato que implícitamente subyacía al derecho contractual clásico era el modelo mercantilista. Este modelo

${ }^{54}$ La tarea principal de esta Escuela era la exégesis de textos del Corpus Iuris a objeto de armonizarlos. El rol trascendental de la exégesis en Francia e Italia se explica por la concepción de los códigos como un cuerpo normativo y símbolo de la unidad nacional y política del país. Por lo tanto, el método sistemático -cuyo objeto es deducir reglas de derecho positivo a partir de conceptos generales y axiomas- no se ajustaba bien.

${ }^{55}$ Véase: Zimmermann, Reinhard, The New German Law of Obligations, cit. (n. 2), passim.

${ }^{56}$ Mason, A F, Contract, Good Faith and Equitable Standards in Fair Dealing, en Law Quaterly Review, 116 (2000), p. 70. 
está basado esencialmente en los siguientes elementos. Primero, el acuerdo de las partes en 'condiciones de mercado', en el lenguaje legal; esto acarreaba la noción que cada uno confiaba en sus propias capacidades y en su propio juicio y que ninguno tenía una obligación de confianza con el otro" 57 .

Como se esbozó, esta investigación ofrece las siguientes teorías para explicar la inexistencia del principio general de la buena fe en el derecho inglés.

a) Primera teoría: la debilidad de la law merchant inglesa. La lex mercatoria fue absorbida por la ley de Inglaterra en virtud de la iniciativa de lord Mansfield en el siglo XVIII ${ }^{58}$. Sin embargo, la buena fe, el principio esencial de la lex mercatoria, no fue recibido. Se postula que esto se debe a la falta de desarrollo de la law merchant en los tribunales mercantiles de Inglaterra. El escaso desarrollo de los tribunales mercantiles ingleses se atribuye a la fortaleza de los tribunales del common law, los cuales, en los hechos, se impusieron a los primeros ${ }^{59}$. Stuart Sutherland añade otras razones para explicar el escaso desarrollo de los tribunales mercantiles en Inglaterra -mientras éstos prosperaban en otros lugares-. La primera razón es el sostenido crecimiento de la Admiralty Court, la cual llegó a su apogeo en el siglo XVI. Otra causa de la falta de desarrollo de la law merchant en los tribunales mercantiles fue la división entre comerciantes y mercantes, "Para el inglés el mercante era esencialmente el exportador, con su negocio organizado en el extranjero. Por ello, un centro de intercambio inglés fue difícil de desarrollar, y cuando se desarrolló fue sólo una pequeña rama del gran mercado de intercambio organizado en el exterior" ${ }^{60}$.

Además, de acuerdo con Farnsworth, en el siglo XVIII -cuando la law merchant había sido absorbida en el common law- el tipo de buena fe que encontró cabida en materias comerciales en las Cortes del Rey era una buena fe subjetiva o la creencia de actuar honesta o correctamente. Esto se debía al hecho que las cortes estaban concentradas en el desarrollo de una doctrina que potenciara la libre circulación de las mercancías y documentos comerciales. Por lo tanto, la buena fe subjetiva (la misma buena fe de la compraventa), no la buena fe obligacional (como un canon de comportamiento), era la preocupación de esos días ${ }^{61}$.

${ }^{57}$ Aттуан, Patrick, cit. (n. 5), p. 402.

${ }^{58}$ Para profundizar el argumento, se recomienda examinar: OldHam, J., English Common Law in the Age of Mansfield (Chapel Hill, University of North Carolina Press, 2004). El estadio previo de co-existencia de la law merchant con el common law puede ser iluminado por el trabajo de: BAKer, J. H., The Law Merchant and the Common Law Before 1700, en Cambridge Law Journal, 38 (1979), pp. 295 ss. Baker sugiere que la distinción entre la lex mercatoria y la ley del Reino de Inglaterra era sólo procedimental. También arguye que los tribunales del common law no "incorporaron" la law merchant, sino que llevaron a cabo un proceso de "refinamiento" del common law "el cual siempre ha gobernado las cuestiones mercantiles" (p. 322).

${ }^{59}$ Cf. BAKer, J. H., cit. (n. 58), p. 306.

${ }^{60}$ Stuart Sutherland, L., The Law Merchant in England in the Seventeenth and Eighteenth Centuries, en Trans. Royal Hist. Soc'y., 17 (1934), pp. 154-156.

${ }^{61}$ Los casos emblemáticos incluían el test de la buena fe para el tenedor de un instrumento negociable. En 1801, en “Lawson v. Weston”, Lord Kenyon decidió que el tenedor no necesitaba inquirir diligentemente cuando entraba en posesión del instrumento, $y$-con la radical predicción que requerir tal examen significaría 'paralizar de una vez la circulación de instrumentos en el país' - introdujo el test subjetivo de la buena fe, el test del 'corazón puro, cabeza limpia'. En 
b) Segunda teoría: la formación de la doctrina de la "consideration”. Reputados estudios revelan la influencia del derecho canónico y del derecho civil sobre las ideas jurídicas de todos los nacientes estados de Europa occidental durante la Edad Media ${ }^{62}$. Este proceso también incluyó a Inglaterra. Holdsworth indica que durante los siglos XII y XIII "La influencia del derecho civil y el derecho canónico es la más importante de todas las influencias externas que moldearon el desarrollo del derecho inglés" ${ }^{63}$. Sin embargo, el principio de la buena fe, clave en los derechos civil y canónico, no fue consagrado como un principio general en el derecho inglés.

Los clérigos-juristas de los siglos XII y XIII introdujeron el concepto romanocanónico de "consciencia" en Inglaterra ${ }^{64}$. Incluso durante el siglo XIV sentencias ocasionales se referían a la "consciencia" o se pronunciaban sobre la base de la misma ${ }^{65}$. Holdsworth se manifiesta a favor de la influencia de esta noción sobre el diseño de la Chancery Court ${ }^{66}$. El mismo autor establece que la equidad también fue administrada por las cortes del common law ${ }^{67}$. Sin embargo, en la segunda mitad del siglo XIV y en el siglo XV el common law tendió a convertirse en un sistema fijo y rígido debido a la falta de conexión con el rey -la discreción real estaba a la base de la modificación equitativa del derecho-. Esta rigidez determinó el desarrollo de un conjunto de principios de equidad e ideas fuera del common law y principalmente administradas por los chancellors.

c) ¿Qué teoría del contrato sustentaban los juristas eclesiásticos? La pregunta puede ser respondida si se examina el tipo de prueba que estos juristas aplicaban para identificar un acuerdo vinculante. Los canonistas de ese período enfatizaban el carácter vinculante del consentimiento, el cual imponía una obligación en conciencia y buena fe. Ellos decían que una obligación deriva

1824, en "Gill v. Cubitt", el test subjetivo de la buena fe fue abandonado por un test objetivo, el cual requería al tenedor ejercer la prudencia y cautela de un hombre razonable. Sin embargo, en 1836 "Gill v. Cubitt” habría de ser superado en Inglaterra”. FARnswOrTH, Allan, Good Faith Performance and Commercial Reasonableness Under the Uniform Commercial Code, en University of Chicago Law Review, 30 (1963), p. 670.

${ }^{62}$ Véase: Holdsworth, William, A History of English Law (4a edición, London, Sweet and Maxwell, 1936), II, pp. 143 ss.; SEIPP, D, The Reception of Canon Law and Civil Law in the Common Law Courts Before 1600, en Oxford Journal of Legal Studies (1993), pp. 388 ss.; y TurNER, R, Roman Law in England Before the Time of Bracton, en J. Brit. Stud., 15 (1975), pp. 1 ss.

${ }^{63}$ Holdsworth, cit., (n. 62), p. 146. La influencia canónica sobre el procedimiento civil inglés es subrayada específicamente por Hazeltine, H. D., Roman and Canon Law in the Middle Ages. The Cambridge Medieval History (Cambridge, Cambridge University Press, 1964), V, pp. 756 ss.

${ }^{64}$ Jeremy, Anthony, "Pacta sunt servanda": The Influence of Canon Law Upon the Contractual Obligation of Good Faith (LLM thesis, Gales, UWC, 1999), p. 41. Véase también: JeremY, Anthony, "Pacta sunt servanda": The Influence of Canon Law Upon the Development of Contractual Obligations, en Law and Justice: the Christian Law Review, 144 (2000), p. 4 ss.

${ }^{65}$ Holdsworth, William, cit., (n. 62) pp. 344 y 346.

${ }^{66}$ HoldsworTh, William, cit., (n. 62) p. 346. El desarrollo de una corte de equidad distinta y separada, la Chancery Court, tuvo lugar en la última parte del siglo XV y, luego, en el siglo XVI.

${ }^{67}$ HoldsworTh, William, The Early History of Equity, en Michigan Law Review, 13 (1915), pp. 293 ss. En la página 294 el autor cita un número importante de estudios para fundar esta posición. 
"non ex nuda sed ex sola promissione" ${ }^{68}$. Los canonistas propagaron la doctrina del pacta sunt servanda, en virtud de la cual simples acuerdos y promesas desnudos deben ser vinculantes. La siguiente es la definición de Bernardus Papiensis en Summa Decretalium 1,26,1.: "Pactum est plurium in idem dandum vel faciendum consensu" " Para que tales acuerdos obtuvieran reconocimiento, los canonistas propusieron que un acuerdo desnudo era válido si estaba "vestido" por una c a u $s$ a adecuada - el ancestro de la causa del derecho civil actual-.

d) ¿Qué teoría del contrato sustentaban los chancellors medievales? Barbour dice que probablemente la prueba que se aplicaba para distinguir un acuerdo de un contrato era la idea canonista de causa ${ }^{70}$. Los chancellors concluyeron que un acuerdo, precisamente porque era un acuerdo, debía ser exigido. Esto surgió como un correctivo a la rigidez del common law y lo influenció al punto que extendió la esfera del assumpsit (una acción para reclamar daños por incumplimiento de un contrato o acuerdo expreso o implícito que no se celebró bajo sello-seal).

En atención a las relaciones de confianza, la noción de causa de los canonistas fue aceptada por las cortes del common law para dar valor a un parol agreement (acuerdo simple, no celebrado bajo sello) ${ }^{71}$. Sin embargo, se le llamó "consideration”. No tenía la connotación moral del derecho canónico ("Dejad a la Iglesia que se ocupe de ello, si es que puede hacerlo" $)^{72}$, sino que se basaba en una carga para la contraparte ${ }^{73}$. Existía, por lo tanto, una diferencia entre estos dos conceptos

${ }^{68}$ De la misma forma, la buena fe influenció la law merchant. A propósito de esto, MiTcheLL, William, An Essay on the Early History of the Law Merchant (Cambridge, Cambridge University Press, 1904), pp. 102 y 105, señala: "Lentamente, la buena fe minó el principio romano y germánico en virtud del cual, en general, los contratos informales no son vinculantes. Es claro que en el siglo XIV la validez de los nuda pacta en transacciones comerciales era reconocida por los usos mercantiles en Italia, y parece probable que en tribunales comerciales y locales éstos también eran reconocidos en Inglaterra”.

${ }^{69}$ En LasPeyres, E. A. T. (editor), Bernardi Papiensis Faventini Episcopi Summa Decretalium: ad Librorum Manuscriptorum Fidem, Cum Aliis Eiusdem Scriptoris Anecdotis (Graz, 1956), p. 21. Además, "A inicios del siglo XIV Guido de Baysio, más conocido por muchas generaciones de canonistas como Archidiaconus, señaló que secundum simplicitatem canonicam un simple pacto en el derecho canónico tiene precisamente el mismo efecto que una estipulación en el derecho civil". La cita proviene del trabajo de BARTON, J. L., The Early History of Consideration, en Law Quaterly Review, 85 (1969), p. 379. Véase también: LESAFFER, R, The Medieval Canon Law of Contract and Early Modern Treaty Law, en Journal of the History of International Law/ Revue d' Histoire du Droit International (2000), p. 178.

${ }^{70}$ Véase Barbour, Willard Titus, History of Contract in Early English Equity, en VinOGRadofF, Paul (editor), Oxford Studies in Social and Legal History (Oxford, Clarendon Press, 1914), IV, passim, especialmente pp. 152-168.

${ }^{71}$ Una obligación primaria de conciencia y de buena fe-los acuerdos deben ser observadosfundó la responsabilidad en el derecho inglés con el desarrollo del assumpsit, el cual llegó a ser un remedio para los casos de acuerdos simples, orales o escritos, no celebrados bajo sello. Véase: Ames, J B, Parol Contracts Prior To Assumpsit, en Harvard Law Review, 8 (1894-1895), pp. 252 ss.

${ }^{72}$ Vinogradoff, Paul, Reason and Conscience in Sixteenth-Century Jurisprudence, en Law Quaterly Review, 24 (1908), p. 382.

${ }^{73}$ Holdsworth, William, The Early History, cit. (n. 67), p. 301, señala que: "Las ideas provenientes del derecho canónico y de la práctica de los Chancellors eclesiásticos fueron las 
-causa y consideration - en los casos por incumplimiento de contrato ventilados antes las cortes de la Iglesia (fidei laesio) y las cortes reales (assumpsit).

Se considera que la diferenciación entre un concepto objetivo de consideration -adoptado por las cortes del common law- y el deber de conciencia original del derecho canónico -el cual influenció fuertemente la causa del derecho continental- está a la base de la inexistencia de la buena fe como un principio rector en el common law de Inglaterra.

\section{CONClusión}

Se ha establecido que la buena fe ha cumplido un rol importante en cada fase de la historia del derecho occidental.

En el derecho romano clásico sobresale el aspecto ético y práctico de la bona fides. A través de la labor del pretor y los bonae fidei iudicia, la buena fe constituyó uno de los agentes más fructíferos en el desarrollo del derecho contractual.

En el período conocido como derecho romano post-clásico, la buena fe adquirió un significado sustancial y a partir de ella se derivaron reglas de conducta para las partes.

Durante la Edad Media, en las ciudades reconocidas como centros comerciales, la buena fe fue tempranamente incorporada en la lex mercatoria para proteger contra resquicios legales o fraudes. El mero consenso de las partes era suficiente para obligar a los contratantes y, en consecuencia, la buena fe introdujo valores en las transacciones. Durante este período el derecho inglés fue influenciado por: el derecho romano; el derecho canónico; y la costumbre mercantil. Por lo tanto, la buena fe también tuvo cabida en la aplicación del derecho por las cortes del common law. Sin embargo, jamás prosperó como un principio rector. A propósito, se esgrimieron dos teorías originales para explicar las razones de dicha circunstancia.

Los códigos modernos establecen la buena fe como un principio general, puesto que es considerada una deducción lógica del derecho natural -inspirador de los códigos. Con todo, algunas manifestaciones del derecho natural relativas a la buena fe no fueron consagradas en los códigos. Por ejemplo, la revisión del contrato debido a nuevas circunstancias cuya presencia determina que el cumplimiento sea más gravoso o imposible. Como es sabido, en muchos códigos dicha posibilidad (rebus sic stantibus) es producto de un desarrollo posterior.

Como puede deducirse fácilmente, la buena fe siempre ha tenido un rol principal en la escena mercantil debido a su flexibilidad. Esta aserción no significa aceptar la teoría que caracteriza a la buena fe como un principio exento de significado, acomodaticio a la interpretación que las partes o el jurista deseen atribuirle en el caso particular. Por el contrario, es posible afirmar que la buena fe es un concepto cuyo significado se determina conforme a los acontecimientos históricos de cada época en que este principio se ha desarrollado.

La historia demuestra cómo ha operado la buena fe en diversos contextos

fuerzas más importantes que inspiraron a los juristas del common law a crear la más distintiva de todas las características del derecho inglés de los contratos -la doctrina de la consideration". 
y eso ayuda a entender las diferentes interpretaciones atribuidas al principio en sistemas jurídicos nacionales y transnacionales actuales. Específicamente, la parte dedicada a Inglaterra permite asumir que la buena fe estuvo presente en ese sistema legal y que sólo por circunstancias históricas, sin mayor peso teórico o filosófico, quedó relegada a ejercer su influencia en casos particulares. Es deseable que este conocimiento pueda contribuir a un mejor entendimiento entre juristas pertenecientes a diversas tradiciones.

\section{BiBLIOGRAFÍA}

Ames, J B, Parol Contracts Prior To Assumpsit, en Harvard Law Review, 8 (1894-1895). Aтіуан, Patrick, The Rise and Fall of Freedom of Contract (Oxford, Oxford University Press, 1979).

BAKer, J. H., The Law Merchant and the Common Law Before 1700, en Cambridge Law Journal, 38 (1979).

Barbour, Willard Titus, History of Contract in Early English Equity, en VinogradofF, Paul (editor), Oxford Studies in Social and Legal History (Oxford, Clarendon Press, 1914), IV.

Barton, J. L., The Early History of Consideration, en Law Quaterly Review, 85 (1969), p. 379. Véase también: LESAFFER, R, The Medieval Canon Law of Contract and Early Modern Treaty Law, en Journal of the History of International Law/Revue d Histoire du Droit International (2000), p. 178.

BONELl, Michael Joachim, Un "codice" internazionale del diritto dei contratti. I Principi UNIDROIT dei Contratti Commerciali Internazionali (Milano,Giuffrè, 2006).

Cardilli, Riccardo, La "buona fede" come principio di diritto dei contratti. Diritto Romano e America Latina, en Garofalo, Luigi (editor), Il ruolo della buona fede oggettiva nell esperienza giuridica storica e contemporanea: atti del convegno internazionale di studi in onore di Alberto Burdese (Padova, Cedam, 2003).

CARVAJAL, Lorena, La buena fe en derecho continental y en derecho anglosajón, en VV. AA., Cuartas Jornadas de Derecho Comercial (en prensa).

CaSARegis, Giuseppe Lorenzo Maria, Discursus legales de commercio ed de avariis (Genova, 1707).

D'Ors, Álvaro, Derecho privado romano (Pamplona, Ediciones Universidad de Navarra, 1968).

Donahue, Charles, The Civil Law in England, en Yale Low Journal, 84 (1974),

Farnsworth, Allan, Good Faith Performance and Commercial Reasonableness Under the Uniform Commercial Code, en University of Chicago Law Review, 30 (1963).

Fascione, L., Cenni bibliografici sulla bona fides, en Studi sulla buona fede (Milano, Giuffrè, 1975).

Fauvarque-Cosson, Bénédicte - Mazeaud, Denis (editores), European Contract Law, Materials for a Common Frame of Reference: Terminology, Guiding Principles, Model Rules (Munich, Sellier, 2008).

Gross, Charles, The Court of Piepowder, en The Quarterly Journal of Economics, 20 (Oxford, 1906) 2.

Hazeltine, H. D., Roman and Canon Law in the Middle Ages. The Cambridge Medieval History (Cambridge, Cambridge University Press, 1964), V. 
Holdsworth, William, A History of English Law (3a edición, London, Sweet \& Maxwell, 1945), V.

Holdsworth, William, A History of English Law (4a edición, London, Sweet and Maxwell, 1936), II.

Holdsworth, William, The Early History of Equity, en Michigan Law Review, 13 (1915).

Jeremy, Anthony, "Pacta sunt servanda": The Influence of Canon Law Upon the Contractual Obligation of Good Faith (LLM thesis, Gales, UWC, 1999).

Jeremy, Anthony, "Pacta sunt servanda": The Influence of Canon Law Upon the Development of Contractual Obligations, en Law and Justice: the Christian Law Review, 144 (2000).

Laspeyres, E. A. T. (editor), Bernardi Papiensis Faventini Episcopi Summa Decretalium: ad Librorum Manuscriptorum Fidem, Cum Aliis Eiusdem Scriptoris Anecdotis (Graz, 1956).

LATTES, Alessandro, Il diritto commerciale nella legislazione statutaria delle città italiane (Milano, Hoepli, 1884).

LOMBARDI, G, Ricerche in tema di "ius gentium" (Milano, Giuffrè, 1946).

Lombardi, L, Dalla "fides" alla "bona fides" (Milano, Giuffrè, 1961).

MAfFeI, Domenico, Gli inizi dell Umanesimo giuridico (Milano, Giuffrè, 1956).

Magnus, U., Germany's Contribution to European and Comparative Law, en Bracton Law Journal, 38 (2006).

Maitland, Frederick William, English Law and the Renaissance (Cambridge, Cambridge University Press, 1901).

MAlynes, Gerard, "Consuetudo vel lex mercatoria" (1622, reimpresión Oxford, Professional Books, 1981).

Mason, A F, Contract, Good Faith and Equitable Standards in Fair Dealing, en Law Quaterly Review, 116 (2000).

MEYER, Rudolf, Bona fides und lex mercatoria in der europäischen Rechtstradition (Göttingen, Wallstein, 1995).

Mrtchell, William, An Essay on the Early History of the Law Merchant (Cambridge, Cambridge University Press, 1904).

Oldham, J., English Common Law in the Age of Mansfield (Chapel Hill, University of North Carolina Press, 2004).

PufENDORF, Samuel, De jure naturae et gentium libri octo (1688, traducción inglesa de C. H. Oldfather y W. A. Oldfather, Oxford, Clarendon Press, 1934).

RentTo, Juha-Pekka, Between Clarence Thomas and Saint Thomas: Beginnings of a Moral Argument for Judicial Jusnaturalism, en University of California Davis Law Review, 26 (1992).

RoDOtÀ, Stefano, Il tempo delle clausule generali, en VV. AA., Il principio della buona fede (Milano, Giuffrè, 1987).

SAMPER, Francisco, Derecho romano (Santiago, Ediciones Universidad Internacional SEK, 1991).

SAnborn, Frederic Rockwell, Origins of the Early English Maritime and Commercial Law (Buffalo, Hein \& Co., 2002).

Schermaier, M. J., Bona fides in Roman Contract Law, en Zimmermann, Reinhard WhitTAKer, Simon (editores), Good faith in European Contract Law (Cambridge, Cambridge University Press, 2000). 
SEIPP, D, The Reception of Canon Law and Civil Law in the Common Law Courts Before 1600, en Oxford Journal of Legal Studies (1993).

SENIOR, William, Doctor's Commons and the Old Court of Admiralty; a Short History of the Civilians in England (London, Longmans, 1922)

Serrao, Feliciano, La "iurisdictio" del pretore peregrino (Milano, Giuffrè, 1954).

Stuart Sutherland, L., The Law Merchant in England in the Seventeenth and Eighteenth Centuries, en Trans. Royal Hist. Soc'y., 17 (1934).

Summers, R., The Conceptualisation of Good Faith in American Contract Law: A General Acccount, en Zimmermann, Reinhard - WhitTAKer, Simon (editores), Good faith in European Contract Law (Cambridge, Cambridge University Press, 2000).

Tetley, William, Good Faith in Contract. Particularly in the Contracts of Arbitration and Chartering, en Journal of Maritime Law and Commerce, 35 (2004).

Thorne, S. E, Henry de Bracton 1268-1968: a Lecture Delivered in Exeter on 27th September 1968 on the occasion of the 700th anniversary of the death of Henry de Bracton (Exeter, University of Exeter 1970).

Thorne, S. E., Statuti in the Post-Glossators, en Speculum, 11 (Cambridge Ma., 1936).

Turner, R, Roman Law in England Before the Time of Bracton, en J. Brit. Stud., 15 (1975).

van Caenegem, R. C., An Historical Introduction to Private Law (Cambridge, Cambridge University Press, 1992).

Vinogradoff, Paul, Reason and Conscience in Sixteenth-Century Jurisprudence, en Law Quaterly Review, 24 (1908).

Vinogradoff, Paul, Roman Law in Medieval Europe (2a edición, Oxford, Oxford Clarendon Press, 1929).

Volckart, O. - Mangels, A, Are the Roots of the Modern "lex mercatoria" Really Medieval? en Southern Economic Journal, 65 (1999).

WhitTaker, Simon - Zimmermann, Reinhard, Good faith in European Contract Law: Surveying The Legal Landscape, en Zimmermann, Reinhard - Whittaker, Simon (editores), Good faith in European Contract Law (Cambridge, Cambridge University Press, 2000).

WiEACKER, Franz, El principio de la buena fe (traducción castellana de José Luis Carro, Madrid, Civitas, 1982).

WiEACKer, Franz, Foundations of European Legal Culture, en American Journal of Comparative Law, 38 (1990).

WIEACKER, Franz, The Importance of Roman Law for Western Civilization and Western Legal Thought, en Boston College International and Comparative Law Review, 4 (1981).

Zimmermann, Reinhard, Roman Law, Contemporary Law, European Law. The civilian Tradition Today (Oxford, Oxford University Press, 2001).

Zimmermann, Reinhard, The New German Law of Obligations. Historical and Comparative Perspective (Oxford, Oxford University Press, 2005). 